\title{
Adipose tissue biomarkers and systemic health
}

\author{
Constantin STEFANI ${ }^{1,2}$, Daniela MIRICESCU ${ }^{3}$, Alexandra TOTAN ${ }^{3}$, Maria GREABU ${ }^{3}$, \\ Ana Maria Alexandra STANESCU ${ }^{1}$ \\ ${ }^{1}$ Department of Family Medicine, "Carol Davila" University of Medicine and Pharmacy, Bucharest, \\ Romania \\ 2“Carol Davila” University Central Emergency Military Hospital, Bucharest, Romania \\ ${ }^{3}$ Department of Biochemistry, Faculty of Dental Medicine, "Carol Davila" University of Medicine \\ and Pharmacy, Bucharest, Romania
}

\begin{abstract}
Adipose tissue consists primarily of adipocytes, being responsible for storing the body's energy reserves. Adipokines secreted by adipose tissue play important roles in the human body. The purpose of this review is to present the most important adipokines and their involvement in the physiological processes but also in the pathogenesis of numerous systemic diseases commonly associated with obesity.
\end{abstract}

Keywords: adipose tissue, biomarkers, adipokines, obesity, systemic diseases

\section{INTRODUCTION}

Adipose tissue is mainly composed of adipocytes, but also presents pre-adipocytes, macrophages, firbroblasts, endothelial cells and leukocytes. At the level of adipose tissue are found the energy reserves of the body, namely triglycerides, synthesized by lipogenesis. The storage of triglycerides in the adipose tissue is unlimited, thus leading to the installation of obesity (1). The process of lipolysis represents the broken down of triglycerides with release of glycerol and fatty acids, which enter into circulation and are taken up by different organs such as liver or muscles for energy purposes (2). Adiponectin, apelin, vaspin, omentin, visfatin, hepcidin, chemerin, fibroblast growth factor 21 (FGF21), fatty-acid-binding protein-4 (FABP4) are adipokines secreted by adipose tissue and are involved in many systemic disorders associated mainly with obesity. The action of adipokines consists in their binding to corresponding receptors of the target cell membrane which will further activate various intracellular signaling pathways (3).

\section{ADIPONECTIN}

Is the most abundant circulating peptide hormone, which has been shown to present anti-inflammatory, cardioprotective and insulin sensitive properties in animal studies (4). Low serum levels of adiponectin have been observed in obesity and obesity-associated disorders (5).

Adiponectin is an anti-atherosclerotic factor that inhibits proliferation of smooth muscle cell proliferation, inhibits macrophage transformation into foam cells, suppresses the production of reactive oxygen species and increases nitric oxide production. Adiponectin is negatively associated with triglycerides and markers of inflammation such as C-reactive protein and positive with HDL. There are studies that have not found an association be- 
tween adiponectin and cardiovascular disease, but other studies confirm a positive association (6-8).

The liver is the main target tissue of adiponectin action and contributes to its insulin sensitizing effect. Adiponectin activates AMP-activated protein kinase (AMPK) and thus reduces the expression of enzymes involved in gluconeogenesis such as phosphoenolpyruvate carboxylase and glucose-6-phosphatase and gluconeogenesis inhibation $(9,10)$.

The action of adiponectin depends on the level of hepatocytes, muscles and other organs of AMP activation. Adiponectin suppresses the liver ceramide amount by enhancing the specific enzyme ceramidase, improving in this way hepatic and whole body insulin sensitivity independent of AMPK (11). Adiponectin can modulate the biological effects of platelet-derived growth factors such as FGF, heparin-binding epidermal growth factor-like growth factor (HB EGF). In the skeletal muscle, the globular form of adiponectin activates the AMPK signaling pathway, increases phosphorylation of acetyl CoA carboxylase, oxidation of fatty acids and glucose uptake (12). Another important role of adiponectin is its involvement in the regulation of thermogenesis process and energy homeostasis (13).

To date, the exact role of adiponectin is not known if it suppresses or promotes thermogenesis and energy homeostasis. The biological effects of adiponectin manifest as a result of its binding to the 2 receptors: adipoR1 and Adipo R2 and T-cadherin (14). Skeletal muscle present adipoR1, hepatocyte adipo R2, T-catherin is expressed ubiquitously (15).

\section{OMENTIN}

Also named intelectin, is produced by visceral adipose tissue and in small amounts can be produced by subcutaneous adipose tissue. Omentin was identified at the level of the heart, lungs, ovary and placenta (16). Omentin is negatively associated with visceral fat, lower levels of omentin have been associated with type 2 diabetes, cardiovascular diseases and metabolic syndrome (17). In vitro, it has been observed that omentin increases insulin-stimulated glucose uptake and the AKT (protein kinase B) signaling pathway activation. In C2C12 monocytes, omentin activates AMPK by phosphorylation which plays an important role in energy metabolism $(16,18)$. Cantarini $L$ et al. detected in juvenile idiopathic arthritis patients increased significantly serum omentin levels versus healthy controls (19).
Choi JH et al. obtained decreased plasma levels of omentin in non-obese women with polycystic ovary syndrome (20). In human endothelial cells, omentin decresed C-reactive protein and TNF- $\alpha$ levels (21). The plasma levels of omentin and the expression of omentine mRNA in visceral adipose tissue is decreased in obese patients (22). August $T$ et al. detected low levels of omentin in patients with metabolic syndrome and morbidly obese women (23). Circulating omentin levels are negatively correlated with body mass index, waist circumference and circulating leptin levels. Patients with type 1 diabetes present decreased levels of omentin and elevated of adiponectin (24). In contrast Yilmaz $Y$ et al. detected increased circulating levels of omentin in patients with non-alcoholic hepatic steatosis (25). Omentin may induce blood vessel vasodilation and may modulate inflammation-induced angiogenesis by activating signaling pathways of the nuclear factor $B(N F-K b)(26)$. The low level of omentin may be the link between obesity, inflammation and cardiovascular diseases. A positive association was observed between omentin and colorectal cancer even in nonobese patients (27).

\section{APELIN}

Is a recently discovered vasoactive peptide present in smooth muscle cells from the heart and endothelium of the vascular wall, but which can also be produced by adipocytes. In the systemic circulation, apelin induces nitric oxide-dependent vasodilation, prevents vasoconstriction caused by angiotensin II and presents cardioprotective effects (28). Hijazi $Z$ et al. detected low levels of apelin in patients with arterial fibrillation compared to healthy subjects. Patients with coronary heart disease, unstable angina, myocardial infarction present decreased circulating levels of apelin (29). In patients with pulmonary arterial hypertension, lower plasma levels of apelin and low expression in human endothelial cells were detected (30). Decreased circulating concentrations of apelin have been observed especially in the Caucasian population correlating with an increased incidence of hypertension (31). Patients with cardiovascular disease present decreased apelin levels, thus suggesting the cardioprotective effect and an important regulator of the immune response (32).

\section{RESISTIN}

Is a cysteine-rich peptide, that can induce lowgrade inflammation by stimulating monocytes in 
humans (33). In rodents, resistin is a hormone secreted by adipocytes, while in humans it is expressed and secreted especially by macrophages, which is associated with obesity and insulin resistance (34). In obese rodents, increased circulating levels of resistin have been observed, and was implicated in obesity-induced insulin resistance and type 2 diabetes (35). Central administration of resistin determines whole bogy insulin resistance by downregulation of adiponectin signalling and induces resistance to FGF 21 (36). Increased serum levels of resistin have been associated with a high severity of cardiovascular diseases (37). Resistin treatment may result in the production of inflammatory cytokines, such as TNF- $\alpha$ and IL-6, molecules adhesion and even chemokines such as ICAM1 (Intercellular Adhesion Molecule 1) and VCAM1(Vascular Cell Adhesion Molecule 1) (38). Clinical trials conducted by Degawa Yamaguchi et al. and Gerber et al. revealed increased circulating levels of resitin in diabetic and obese patients, correlating with aging $(39,40)$. Instead Lee JH et al. reported that the circulating levels of resistin are not correlated with obesity and insulin resistance (41).

\section{FABP4}

Is a member of the cytoplasmic fatty- acid- binding protein superfamily, which can be expressed by adipocytes and macrophages (42). Rats studies that received a fat diet, this protein was associated with insulin resistance (43). Reiser $\mathrm{H}$ et al. detected a positive association between high concentrations of FABP4 and an increased incidence of obesity-specific cardiovascular diseases (44).

\section{FGF 21}

FGF21 plays various roles in metabolism and may be defined as hepatokine, adipokine and myokine (45). FGF21 as adipokine is induced in response to cold exposure, further promoting thermogenic gene expression in brown adipose tissue and inguinal white adipose tissue (46). In white and brown adipose tissue, FGF 21 action is mediated through the $1 \mathrm{c}$ receptors and the beta-klotho coreceptor (47). In the white adipose tissue FGF 21 manifests its metabolic effects on body weight, glycemic homeostasis, and plasma triglycerides (48). In obese and type 2 diabetic patients, circulating levels of FGF21 had been increased (49).

\section{VASPIN}

Vaspin was initially isolated in visceral white adipose tissue in rats with type 2 diabetes by Hida
$K$ et al. So far, the mechanism of action of vaspin is not fully elucidated, there are studies that confirm a positive correlation between vaspin gene expression and metabolic syndrome or insulin resistance $(50,51)$. Kim et al. did not detect a change in vaspin level in patients with metabolic syndrome who followed a 10-month diet (52). Mansour SW et al. conducted a study that included obese diabetic women. Vaspin showed decreased level in obese diabetic patients after 6 months of the mediterranean diet compared with control (53).

\section{VISFATIN}

Visfatin is secreted by human peripheral blood lymphocytes as pre $B$ colony improvement Factor (PBEF), which acts like the nicotinamide phosphoribosyl transferase enzyme, involved in the $\mathrm{NAD}^{+}$ salvage pathway (54). Fukuhara et al. identified PBEF as visfatin as a new adipokine secreted in higher levels by visceral fat cells (55). Visfatin is considered a new proinflammatory adipokine that can influence the production of pro or anti-inflammatory cytokines such as IL-1 $\beta$, IL-1Ra, IL-6, IL10, TNF- $\alpha$ in human monocytes (56). Increased circulating levels of visfatin have been reported in patients with rheumatoid arthritis, acute lung injury, inflammatory conditions such as bowel disease or psoriasis (57-59).

\section{HEPCIDIN}

Hepcidin is a peptide hormone composed of 25 amino acid residues, which regulates the iron absorption and its distribution to specific tissues. This peptide hormone is synthesized by hepatocytes but in lower concentrations it can be expressed by macrophages, adipocytes and brain. Hepcidin deficiency is associated with hereditary hemochromatosis, feriprive anemia and hepatitis $C(60)$.

\section{CHEMERIN}

Chemerin is a chemoattractant for immune cells, being also an adipokine that regulates adipogenesis, angiogenesis and energy metabolism (61. Rourke JL et al. reported a positive association between chemerin and obesity-associated systemic disorders such as insulin resistance, serum triglyceride levels and body mass index (62). Serum levels of chemerin are elevated in obese or overweight individuals and in persons with insulin resistance $(63,64)$. To date, there has been no association between this adipokine and the metabolic syndrome. In chronic inflammatory conditions, positive corre- 
lations were observed between chemerin and inflammatory cytokines such as C-reactive protein. Chemerin is involved in the pathogenesis of chronic kidney disease, psoriasis, chronic inflammatory disease, chronic rheumatoid arthritis $(65,66)$. In cancer pathogenesis can be may present pro or anti-carcinogenic effects (67).

\section{CONCLUSIONS}

Adipose tissue is not only an energy storage organ and is also an important endocrine organ. Ad- ipocytes secrete numerous adipokines that are involved in numerous physiological and pathological processes most often associated with obsesity-induced systemic disorders.

\section{Acknowledgement}

All authors equally contributed to the present paper.

\section{Conflict of interest: none declared Financial support: none declared}

\section{REFERENCES}

1. Tan CY, Vidal-Puig A. Adipose tissue expandability: the metabolic problems of obesity may arise from the inability to become more obese. Biochem Soc Trans 2008; 36 935-940.

2. Frayn KN. Adipose tissue as a buffer for daily lipid flux. Diabetologia 2002; 45 1201-1210.

3. Andrade-Oliveira V, Camara NO, Moraes-Vieira PM. Adipokines as drug targets in diabetes and underlying disturbances. J Diabet Res 2015; 2015 681612.

4. Turer AT, Scherer PE. Adiponectin: mechanistic insights and clinical implications. Diabetologia 2012;55: 2319-26.

5. Schondorf T, Maiworm A, Emmison $\mathrm{N}$ et al. Biological background and role of adiponectin as marker for insulin resistance and cardiovascular risk. Clin Lab 2005;51:489-94.

6. Wu Z, Cheng Y, Aung LH et al. Association between adiponectin concentrations and cardiovascular disease in diabetic patients: a systematic review and meta-analysis. PLoS One 2013;8(11):e78485.

7. Kanhai DA, Kranendonk ME, Uiterwaal CS et al. Adiponectin and incident coronary heart disease and stroke. A systematic review and meta-analysis of prospective studies. Obes Rev 2013;14(7):555-67.

8. Zhang $\mathrm{H}, \mathrm{Mo} X, \mathrm{Hao} Y$ et al. Adiponectin levels and risk of coronary heart disease: a meta-analysis of prospective studies. Am J Med Sci 2013;345(6):455-61.

9. Combs TP, Pajvani UB, Berg AH et al. A transgenic mouse with a deletion in the collagenous domain of adiponectin displays elevated circulating adiponectin and improved insulin sensitivity. Endocrinol 2004;145:367-383.

10. Nawrocki AR, Rajala MW, Tomas E et al. Mice lacking adiponectin show decreased hepatic insulin sensitivity and reduced responsiveness to peroxisome proliferatoractivated receptor gamma agonists. J Biol Chem 2006; 281:2654-2660.

11. Holland WL, Miller RA, Wang ZV et al. Receptor-mediated activation of ceramidase activity initiates the pleiotropic actions of adiponectin. Nat Med 2011; 17:55-63.

12. Tomas E, Tsao TS, Saha AK et al. Enhanced muscle fat oxidation and glucose transport by ACRP30 globular domain: acetyl-CoA carboxylase inhibition and AMP-activated protein kinase activation. PNAS 2002; 99:16309-16313.

13. Hui X, Gu P, Zhang J et al. Adiponectin enhances cold-induced browning of subcutaneous adipose tissue via promoting M2 macrophage proliferation. Cell Metabol 2015; 22: 279-290.

14. Yamauchi T, Nio Y, Maki T et al. Targeted disruption of AdipoR1 and AdipoR2 causes abrogation of adiponectin binding and metabolic actions. Nat Med 2007; 13 : 332-339.

15. Denzel MS, Scimia MC, Zumstein PM et al. T-cadherin is critical for adiponectinmediated cardioprotection in mice. J Clin Invest 2010;120(12):4342-52.

16. Yang RZ, Lee MJ et al. Identification of omentin as a novel depotspecific adipokine in human adipose tissue: possible role in modulating insulin action. Am J Physiol Endocrinol Metab 2006; 290: E1253-61.

17. De Souza Batista CM, Yang RZ et al. Omentin plasma levels and gene expression are decreased in obesity. Diabetes 2007;56:1655-61.

18. Yu D. Omentin activates AMP-activated protein kinase and plays a role in energy metabolism and immune response. PhD dissertation. Molecular Medicine: University of Maryland 2011.

19. Cantarini L, Simonini G, Fioravanti A, et al. Circulating levels of the adipokines vaspin and omentin in patients with juvenile idiopathic arthritis, and relation to disease activity. Clin Exp Rheumatol 2011; 29: 1044-8.

20. Choi JH, Rhee EJ, Kim KH et al. Plasma omentin- 1 levels are reduced in non-obese women with normal glucose tolerance and polycystic ovary syndrome. Eur J Endocrinol 2011; 165: 789-96.

21. Tan BK, Adya R, Farhatullah S et al. Metformin treatment may increase omentin-1 levels in women with polycystic ovary syndrome. Diabetes 2010; 59: 3023-31.

22. Barth S, Klein P, Horbach T, et al. Expression of neuropeptide $Y$, omentin and visfatin in visceral and subcutaneous adipose tissues in humans: relation to endocrine and clinical parameters. Obes Facts 2010; 3:245-51.

23. Auguet T, Quintero Y, Riesco D, et al. New adipokines vaspin and omentin. Circulating levels and gene expression in adipose tissue from morbidly obese women. $B M C$ Med Genet 2011; 12:60.

24. Antoniades C, Antonopoulos AS, Tousoulis $D$ et al. Adiponectin: from obesity to cardiovascular disease. Obes Rev 2009;10:269-79.

25. Yilmaz Y, Yonal O, Kurt R, et al. Serum levels of omentin, chemerin and adipsin in patients with biopsy-proven non-alcoholic fatty liver disease. Scand J Gastroenterol 2011; 46:91-7.

26. Tan BK, Adya R, Randeva HS. Omentin:a novel link between inflammation, diabesity, and cardiovascular disease.Trends Cardiovasc Med 2010;20:143-8.

27. Aleksandrova K, di Giuseppe R, Isermann $B$ et al. Circulating omentin as a novel biomarker for colorectal cancer risk: data from the EPIC-Potsdam cohort study. Cancer Res 2016;76:3862-71.

28. Chandrasekaran B, Dar O, McDonagh T. The role of apelin in cardiovascular function 
and heart failure. Eur $\mathrm{J}$ Heart Fail 2008;10(8):72532.

29. Kadoglou NP, Lampropoulos S, Kapelouzou A et al. Serum levels of apelin and ghrelin in patients with acute coronary syndromes and established coronary artery disease - Kozani Study. Transl Res 2010; 155:238-46.

30. Chandra SM, Razavi H, Kim J et al. Disruption of the apelinAPJ system worsens hypoxia-induced pulmonary hypertension. Arterioscler Thromb Vasc Biol 2011; 31(4):814-20.

31. Xie H, Luo G, Zheng Y et al. Circulating apelin is significantly associated with an increased risk for hypertension :a meta-analysis. Clin Exp Hypertens 2017; 39:435-40.

32. Chen T, Wu B, Lin R. Association of apelin and apelin receptor with the risk of coronary artery disease: A meta-analysis of observational studies. Oncotarget 2015; 8(34).

33. Patel SD, Rajala MW, Rossetti $L$ et al. Disulfide-dependent multimeric assembly of resistin family hormones. Science 2004; 304:1154-8.

34. Patel L, Buckels AC, Kinghorn IJ et al. Resistin is expressed in human macrophages and directly regulated by PPAR gamma activators. Biochem Biophys Res Commun 2003;300: 472-6.

35. Steppan CM, Bailey ST, Bhat S et al. The hormone resistin links obesity to diabetes. Nature 2001; 409: 307-312

36. Benomar Y, Amine H, Crepin D et al.Central resistin/TLR4 impairs adiponectin signaling contributing to insulin and FGF21 resistance. Diabetes 2016; 65:913-926.

37. Zhang JZ, Gao Y, Zheng YY et al. Increased serum resistin level is associated with coronary heart disease. Oncotarget 2017; 8:50148-50154.

38. Verma S, Li SH, Wang $\mathrm{CH}$ et al. Resistin promotes endothelial cell activation: further evidence of adipokine-endothelial interaction. Circulation 2003; 108:736-740.

39. Degawa-Yamauchi M, Bovenkerk JE, Juliar $\mathrm{BE}$ et al. Serum resistin (FIZZ3) protein is increased in obese humans. $\mathrm{J}$ Clin Endocrinol Metabol 2003; 88:5452-5455.

40. Gerber M, Boettner A, Seidel B et al. Serum resistin levels of obese and lean children and adolescents: biochemical analysis and clinical relevance. J Clin Endocrinol Metabol 2005; 90: 4503-4509.

41. Lee JH, Chan JL, Yiannakouris N et al. Circulating resistin levels are not associated with obesity or insulin resistance in humans and are not regulated by fasting or leptin administration: cross-sectional and interventional studies in normal, insulinresistant, and diabetic subjects. J Clin Endocrinol Metabol 2003; 88:4848-4856.

42. Furuhashi M, Hotamisligil GS. Fatty acid-binding proteins: role in metabolic diseases and potential as drugtargets. Nat Rev Drug Discov 2008;7:489-503.

43. Uysal KT, Scheja L, Wiesbrock SK et al. Improved glucose and lipid metabolism in genetically obese mice lacking AP2. Endocrinol 2000; 141:3388-96.

44. Reiser $\mathrm{H}$, Klingenberg $\mathrm{R}$, Hof $\mathrm{D}$ et al. Circulating FABP4 is a prognostic biomarker in patients with acute coronary syndrome but not in asymptomatic individuals. Arterioscler Thromb Vasc Biol 2015;35:1872-9.

45. Kim KH, Jeong YT, Oh H et al.Autophagy deficiency leads to protection from obesity and insulin resistance by inducing Fgf21 as a mitokine. Nat Med 2013; 19: 83-92.

46. Lee JE, Ge K. Transcriptional and epigenetic regulation of PPARgamma expression during adipogenesis. Cell Bioscience 2014; 4:29.

47. Foltz IN, Hu S, King C et al. Treating diabetes and obesity with an FGF21mimetic antibody activating the betaKlotho/ FGFR1c receptor complex. Sci Translat Med 2012; 4:162ra153.

48. Veniant MM, Sivits $G$, Helmering J et al. Pharmacologic effects of FGF21 are independent of the 'browning' of white adipose tissue. Cell Metabol 2105; 21:731-38.

49. Chen WW, Li L, Yang GY et al. Circulating FGF-21 levels in normal subjects and in newly diagnose patients with Type 2 diabetes mellitus. Exp Clin Endocrinol Diabet 2008; 116:65-68.

50. Chang HM, Lee HJ, Park HS et al. Effects of weight reduction on serum vaspin concentrations in obese subjects: modification by insulin resistance. Obesity 2010;18: 2105-10.

51. Bashiri J, Rahbaran A, Gholami F et al. The effect of acute exercise on serum vaspin level and its relation to insulin sensitivity in overweight elderly men. Zahedan J Res Med Sci 2013; 16(8):10-13.

52. Kim SM, Cho GJ, Yannakoulia M et al. Lifestyle modification increases circulating adiponectin concentrations but does not change vaspin concentrations. Metabolism 2011;60:1294-99.

53. Mansour SW, Tawfiq MS, Khalefa AA et al. Effect of Diet Regimen on Serum Vaspin
Level in Obese Diabetic Female Patients. Zagazig Univ Med J 2019;25(5):669-707.

54. Samal B, Sun Y, Stearns $G$ et al. Cloning and characterization of the CDNA encoding a novel human pre-B-cell colonyenhancing factor. Mol Cell Biol 1994;14:14311437.

55. Fukuhara A, Matsuda M, Nishizawa M et al. Visfatin: a protein secreted by visceral fat that mimics the effects of insulin. Science 2005; 307:426-430.

56. Moschen AR, Kaser A, Enrich B et al. Visfatin, an adipocytokine with proinflammatory and immunomodulating properties. J Immunol 2007;178:1748-1758.

57. Otero M, Lago R, Gomez R. Changes in plasma levels of fat-derived hormones: Aiponectin, leptin, resistin and visfatin in patients with rheumatoid arthritis. Ann Rheum Dis 2006; 65: 11981201.

58. Ye SQ, Simon BA, Maloney JP et al. Pre-B-cell colony-enhancing factor as a potential novel biomarker in acute lung injury. Am J Respir Crit Care Med 2005; 171: $361-370$

59. Koczan D, Guthke R, Thiesen HJ et al. Gene expression profiling of peripheral blood mononuclear leukocytes from psoriasis patients identifies new immune regulatory molecules. Eur J Dermatol 2005; 15:251-257.

60. Nemeth E, Ganz T. The Role of Hepcidin in Iron Metabolism. Acta Haematol 2009; 122:78-86.

61. Buechler C. Chemerin in Liver Diseases. Endocrinol Metab Syndr 2014; 3:144.

62. Rourke JL, Dranse HJ, Sinal CJ. Towards an integrative approach to understanding the role of chemerin in human health and disease. Obes Rev 2013;14:245-262.

63. Ernst MC, Sinal CJ. Chemerin: At the crossroads of inflammation and obesity. Trends Endocrinol Metab 2010; 21:660-667.

64. Bozaoglu K, Bolton K, McMillan J et al. Chemerin is a novel adipokine associated with obesity and metabolic syndrome. Endocrinol 2007; 148:4687-4694.

65. Buechler C. Chemerin, a novel player in inflammatory bowel disease. Cell Mol Immunol 2014; 11: 315-316.

66. Fatima SS, Rehman R, Baig M et al. New roles of the multidimensional adipokine: Chemerin. Peptides 2014: 62:15-20.

67. Mariani F, Roncucci L. Chemerin/chemR23 axis in inflammation onset and resolution. Inflamm Res 2015; 64: 85-95. 